\title{
Formation of the modern scenic city of Hangzhou: towards conservation integrated urban planning, 1950s-1990s
}

\author{
Shulan $\mathrm{Fu}^{*}$ and Panpan Jin
}

\begin{abstract}
From the 1950s to the 1990s, China underwent a significant transformation of its political system and economy, from socialism to rapid development after the reform and opening up. In the 1980s and 1990s, to meet the demand for housing and urban modernization under the rapid growth of cities, almost all Chinese cities underwent large-scale urban construction, transformation and expansion. With this background of rapid advancement, many cities have lost their traditional urban features and characteristics. However, it was during this period that Hangzhou not only restored the historical scenery of West Lake through multiple projects but also explored overall planning of the city and introduced conservation ideas, making West Lake, which was originally located outside the city, part of the city. This period also shaped the contemporary urban characteristics of Hangzhou with traditional landscape features. To explore Hangzhou's positive experience and determine the critical junctures and influencing factors, this study observed the entire historical process using morphological methods. Based on a summary of the characteristics of each development stage, this study further focuses on the key issue of how conservation ideas are gradually introduced into urban planning and affect the development process.
\end{abstract}

Keywords: Hangzhou, West Lake, 1950s-1990s, morphological method, conservation, urban planning, scenic city

\section{Introduction}

The construction of Chinese cities from the 1950s to the 1990s went through three distinct periods with different characteristics, the period of learning from Soviet Union's experience of building socialist city, the period of serving the political movements, and the period of absorbing the experience of various countries into a period of rapid construction after the reform and opening up (Zou 2014). In this context, the study of Chinese cities in this period focused on the formation of urban planning systems under the Soviet Union's influences in the 1950s (Li 2016), rapid urbanisation since the 1990s, which is considered globally rare (Wu et al. 2007), and issues in humanities and social sciences, such as the influences of political movements on urban construction (Zhu 2014; Zhu 2015) and the roles of

\footnotetext{
* Correspondence: fushulan@zju.edu.cn China

College of Civil Engineering and Architecture, Zhejiang University, Hangzhou,

(c) The Author(s). 2020 Open Access This article is licensed under a Creative Commons Attribution 4.0 International License, which permits use, sharing, adaptation, distribution and reproduction in any medium or format, as long as you give appropriate credit to the original author(s) and the source, provide a link to the Creative Commons licence, and indicate if changes were made. The images or other third party material in this article are included in the article's Creative Commons licence, unless indicated otherwise in a credit line to the material. If material is not included in the article's Creative Commons licence and your intended use is not permitted by statutory regulation or exceeds the permitted use, you will need to obtain permission directly from the copyright holder. To view a copy of this licence, visit http://creativecommons.org/licenses/by/4.0/. Hangzhou city, the study object in this paper, reflects characteristics that are different from these mainstream perceptions of contemporary Chinese cities. Like other cities, this city has experienced the construction of socialism, political movements, and rapid urban development. However, Hangzhou retains the characteristics of the traditional Chinese landscape, which benefited from consideration of the relationship between the city and the West Lake Scenic area during modern urban construction. Although it now appears that Hangzhou is regarded more as an ancient cultural capital with many heritages (Zhang 2017), in the 1950s, it was considered to be a representative example of contemporary urban construction. Together with the city of Lanzhou, which is currently often regarded as a typical contemporary Chinese city, Hangzhou was chosen for exhibition in the International 
Union of Architects (UIA) congress in Moscow (1958) with the theme of urban renewal.

Hangzhou, which has the characteristics of modern urban construction and well-preserved traditional landscape features, has recently attracted the attention of researchers. Studies have demonstrated that these urban features were related to formation of the city-lake integrated urban form in Hangzhou (Fu 2015), and the main opportunity was the modern planning attempt to change the lake-side banner camp into a new market in 1914 after the revolution (Fu 2016). There were also studies that took Hangzhou as a typical case of modern urban tourism development in China (Wang 1999). However, these studies focused on studying the starting point during the early modern period from the perspective of historical research and did not look further into the process of form completion and its influencing factors from the 1950s to 1990s. Regarding the urban construction of Hangzhou from the 1950s to 1990s, existing studies focused on analysing road patterns and their formation processes in the 1990s (Li 2017), and some studies focused on clarifying the historical details regarding past construction projects and plans in the West Lake Scenic area (Wu 2004; Yang 2008). These studies either focused on a single topic or focused on a shorter development period. Therefore, an objective analysis of the entire process from the 1950s to 1990 s is still needed to observe the formation process and its influencing factors of the modern scenic city of Hangzhou.

With the aim of observing the overall formation process, urban morphology, which aids in analysing the formation process, was introduced into this historical study. The urban morphology method was developed by Conzen in his studies about medieval towns (Conzen 1960), and this method was improved by Whitehand (Whitehand 1987); subsequently, several other scholars (Barrett 1996; Kropf 1996; Barke 2003; Zhang 2003; Bienstman 2007) formed a school of international influence, which was introduced into the studies of Chinese cities during the 1980s (Zheng and Lin 2002). Early attention and introduction focused on one of the key concepts, urban fringe (Wu and Ma 1990). The relatively systematic method was applied after 2000, which was mainly found in the study of small-scale ancient towns, such as Pingyao (Whitehand and Kai 2007a; Whitehand et al. 2011) and historical districts, such as the Zhishanmen historic area in Beijing (Whitehand and Kai 2007b; Yao et al. 2012) and the Liwan Tenth Fu Road Historic District in Guangzhou (Yao et al. 2013). These case studies mainly contributed to the practice of urban conservation. Meanwhile, many studies of urban history began to take the urban form as one key factor of its observation and discussion (Zhou 2005; Chen 2006; Zhang 2008; Fu 2010), although the Conzen method was not necessarily applied. In this context, this article introduces the concept of urban morphology, which not only contributes to observing the historical process and development stages of Hangzhou's modern scenic city but also expands the application of the methodology in the study of Chinese cities.

\section{Analysis and division of historical stages}

To analyse the development process in this paper, materials, such as drawings of the 1951 master plan draft, the 1953, 1958, 1983 and 1992 Hangzhou master plans (Hangzhou Municipal People's Government 1951, $1953,1958,1983,1992 b)$, and the master plan revisions in 1964 and 1996 (Hangzhou Municipal People's Government 1964, 1996b), were used to complete the base maps. In this step, the deviations of these map drafts were corrected by the map-matching method according to satellite maps. In addition, the Hangzhou Yearbook and various local chronicles were used to obtain the details. The Hangzhou Yearbook (Hangzhou Municipal People's Government 1988, 1989, 1990a, 1990b, 1991, 1992a, 1993, 1994, 1995, 1996a, 1997, 1998, 1999, 2000) is a series of books published by the Hangzhou Municipal People's Government since 1988. These books provide detailed information on urban construction and are considered to be the main data sources for this paper. Prior to 1987, the Hangzhou Construction Chronicles provided figures for the construction and renewal projects in the city (Hangzhou Urban and Rural Construction Chronicles Committee 2002). Additionally, several reports related to the construction of Hangzhou at the time were found in newspapers, mainly the People's Daily and the Guang Ming Daily, which provided corroborative evidence. For those contents that are not available because of file confidentiality or other reasons but affect the analysis, interviews with practitioners are supplemented (Fu and Jin 2019).

To ensure plausibility, the first step of analysis is to divide the whole period into 10 units, corresponding to the national five-year plans, which were made to coordinate the construction projects. For each time unit, the changing features of physical elements that affect the entire development process were observed, including new constructions and renewal projects of streets, factories, public green space, residential districts, etc. Within the Conzen School, studies explored the urban development process by defining morphological regions, which focus on the homogeneity and heterogeneity of adjacent plots. However, due to the lack of precise records about urban plots, those important spatial factors were quantized on a large scale as the size of the urbanised area, the length of roads, and the number of construction projects to pursue accurate development trends. Additionally, as the purpose of this research is to observe the historical 
critical junctures of the development process, this study did not go further into space syntax analysis, which is characteristic of most morphological studies; instead, this study discusses the dynamic mechanisms of urban morphological transformation and how the urban conservation idea was introduced and developed in urban planning and construction. The following section further observes the characteristics and influencing factors of morphological changes at each stage.

By data analysis (Fig. 1), the development characteristics that were clarified led to a division of 5 stages. (1) From 1949 to 1957, both the size of the urbanised area and the length of the roads increased rapidly, while the number of construction projects reached the peak. (2) From 1958 to 1964, the number of construction projects declined, while the other two factors steadily increased. (3) From 1965 to 1974, the length of streets continued to increase, while the size of the urbanised area stopped increasing, and the number of construction projects declined to almost zero. (4) From 1975 to 1989, the length of roads continued increasing but in a more rapid way, while the urbanised area and the number of construction projects began to increase again. (5) From 1990 to 2000, the number of urban construction projects did not change, but both the size of the built-up area and the length of urban roads showed a rapid rises. By mapping and literature research, more detailed developing characteristics were found during each stage.

\section{Five stages towards formation of a modern scenic city in Hangzhou (Fig. 2)}

The first stage, from 1949 to 1957, is a period when the lake-city combined urban form was finalized in Hangzhou. This so-called lake-city combined urban form started in the late Qing Dynasty, when the city wall was destroyed and a series of initial modernization efforts were implemented, such as the New Market Plan, West Lake Ring Road, and West Lake Expo ( $\mathrm{Fu}$ 2016). However, until the 1950s, it was only completed as a frame that needs further construction and completion of form. From mapping, we can observe that the urbanised area inside West Lake continued to expand westward by implementing lake environment restoration and the construction projects of recuperation facilities and hotels. On the other hand, the urban area expanded beyond the traditional city boundary identified by Wushan Hill in the south, Wulin in the north, Qiantang River in the east and West Lake in the west. If we compare it with the City Master Plan (1953), which began under the direction of Soviet experts and defined Hangzhou as 'a city of rest and recuperation', the construction

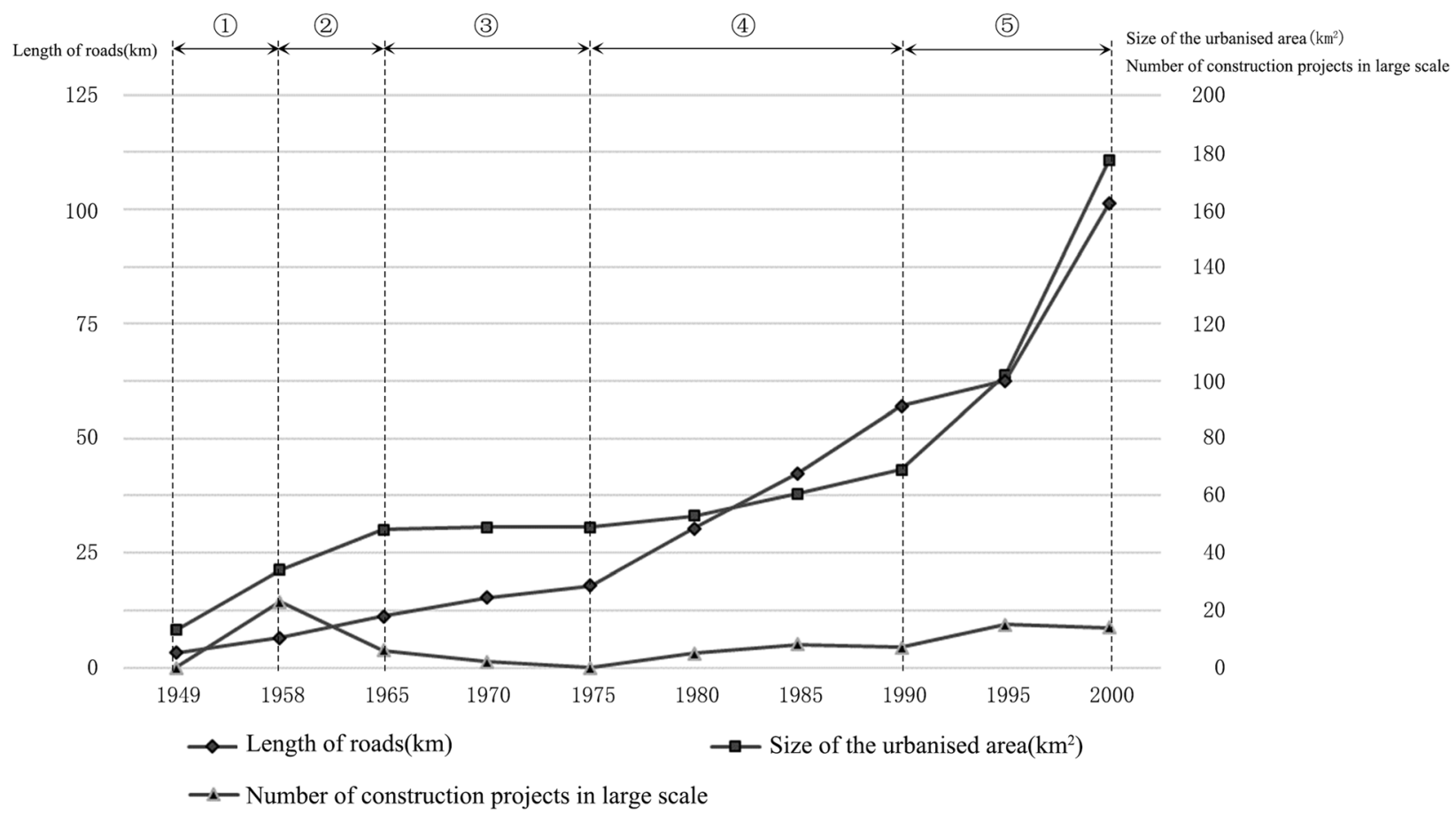

Fig. 1 Construction statistics of Hangzhou from the 1950s to the 1990s. In terms of built-up area, there were no statistical data for the years 1958, 1965, 1970 and 1975. Therefore, the data in the chart were calculated by the authors according to historical maps. In terms of the length of the urban road, this study calculates the total length of the high-grade road with a width of more than $3.5 \mathrm{~m}$. In addition, due to the change in statistical methods and dimensions, the relevant data after 1995 are only for reference (Source: the authors. Data are from the Hangzhou Yearbook) 


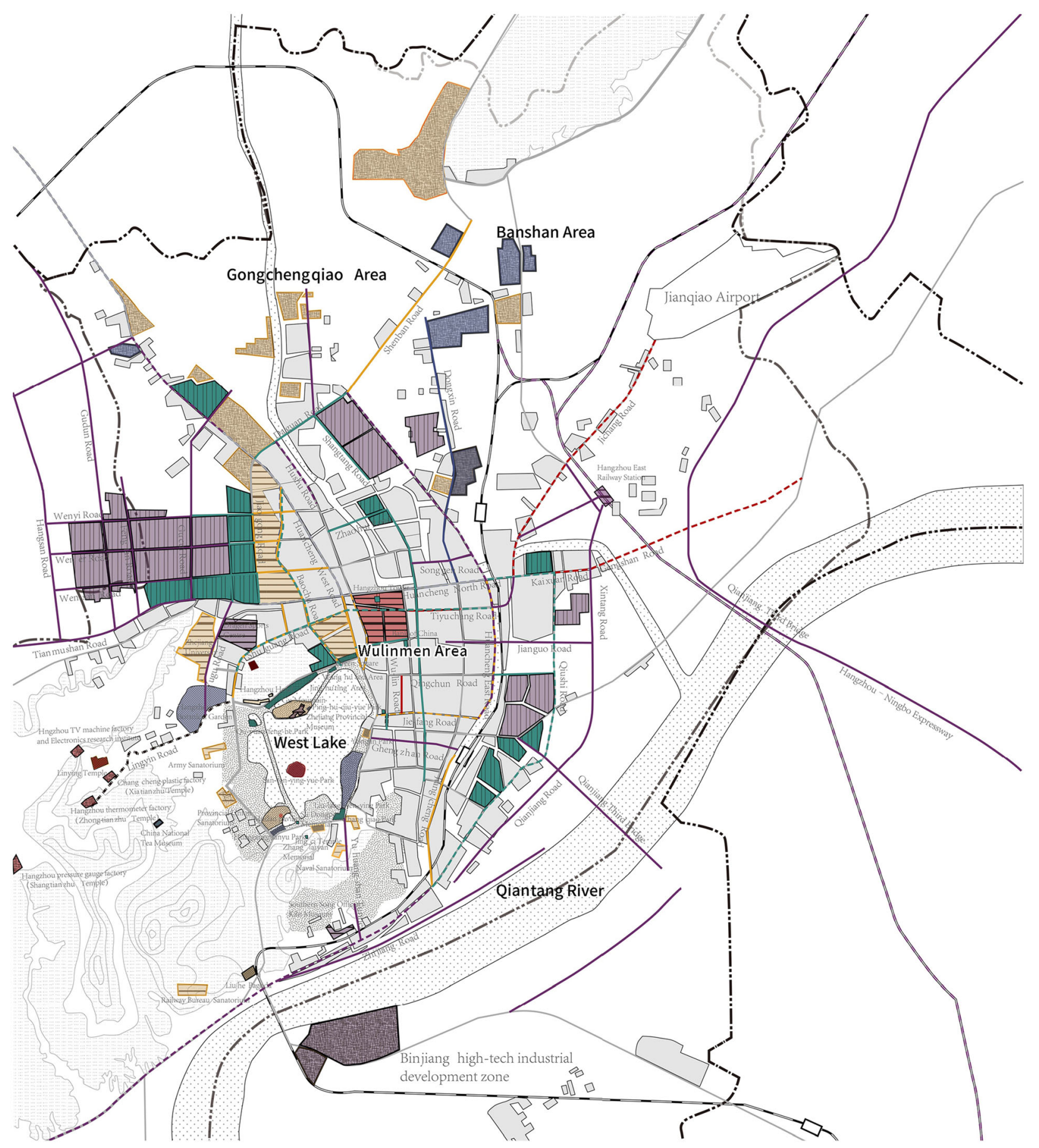

$1949-1957 \quad 1958-1964 \quad 1965-1974 \quad 1975-1989 \quad 1990-2000$

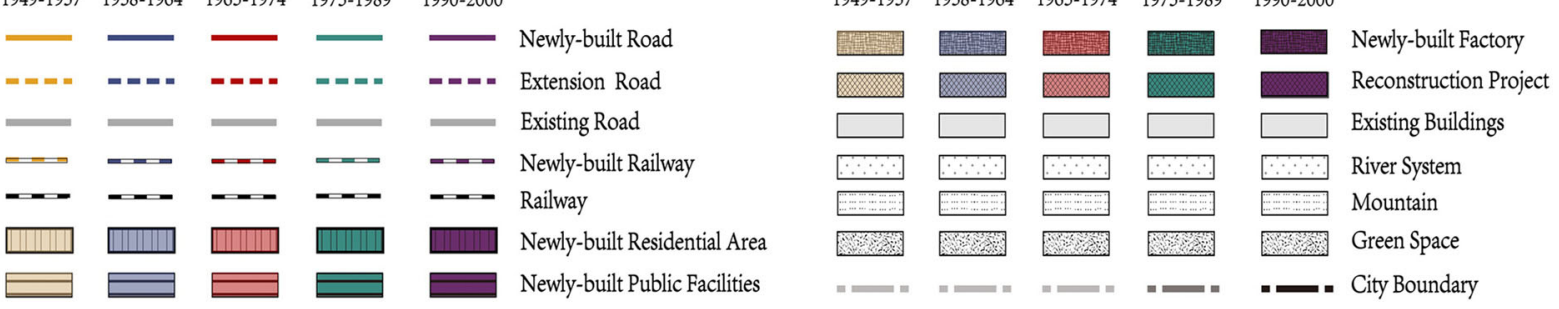

Fig. 2 New Constructions and Renewal Projects of Five Stages (Source: the authors. Data are from the Hangzhou Yearbook and Hangzhou Construction Chronicles) 
during this period nearly followed the master plan, taking West Lake as a centre, building educational facilities on its northern side, recuperation facilities on its southern side, and administrative facilities between the old city and West Lake.

The second stage, which is from 1958 to 1964, is a period that began with frequent political movements, although urban construction was not stopped and continued to occur. The industrial facilities and factories located in the north started during the first five-year plan and ran out as planned by the second five-year plan. Therefore, roads towards the north were constructed, which furthered the expansion of the city to the north. It was the same in the West Lake zone, planned construction was continued, while several new projects were undertaken to meet the needs of diplomatic reception, such as the construction of the second phase of Huagang Guanyu (Viewing Fish at Flower Pond) Park, the restoration of the green belt along Beishan Road, and construction of the airport-connected Jichang Road. This period followed the planning and construction ideas of the previous period, a period that continued to complete the lake-city combined urban form, but as the political movement was intensifying, the number of urban construction projects plummeted.

The third stage, from 1965 to 1974, is the period of the Cultural Revolution, when every decision needed to meet the needs of political principles. Several main roads in the recent city centre were formed during this period to provide a smooth route and enough public space for frequently occurring parades. The parade was always assembled to the east on East Huancheng Road and to the west in Liulang Wenying (Orioles Singing in Weeping Willows) Park on Nanshan Road; then, the flow of people from various aspects of the city passed through Yan'an Road from south to north, through the review platform and Tiyuchang Road from east to west; finally, everyone gathered in front of the Chairman Mao Memorial Hall (now the Zhejiang Provincial Exhibition Hall) in Red Sun Square. Related construction has adjusted the width and connectivity of major arterial roads and built a number of symbolic urban spaces. However, its impact on the overall shape of the city is not great. On the other hand, West Lake, as an existing representative for Olds, ${ }^{1}$ experienced terrible destruction. Not only were temples changed to factories or offices, but gardens and historical monuments, such as stone tablets of Ten Scenes, were also removed. Although several

\footnotetext{
${ }^{1}$ Casting Away Four Olds refers to breaking away from old thoughts, old cultures, old customs and old habits. The idea radically treats all historical legacies as dross and in need of being discarded.

${ }^{2}$ These projects were part of preparations for the arrival of foreign leaders, such as President Richard Nixon of the US and Prince Sihanouk of Kampuchea in 1971.
}

scenic spots were restored for diplomatic use ${ }^{2}$ at the end of this period, West Lake's form changed considerably.

The fourth stage, which was from 1975 to 1989 , is a period of old city centre renewal with large-scale construction of residential districts at the urban fringe. After the reform and opening up, Hangzhou city carried out a comprehensive urban renewal project [jiucheng gaizao in Chinese]. One of these reconstruction projects, the Zhongdong River Renewal Project, which was combined with an elevated highway construction, crossed over the whole city centre from north to south, leading to adjustment of the internal structure of the city. Meanwhile, large-scale construction of residential districts at the urban fringe led to urban expansion. For West Lake, in response to the damage in the previous period, largescale restoration projects were launched. Additionally, to improve public access, an additional 5.84 ha of landscape was reorganized on the north and northeast sides ( $\mathrm{Yu}$ and Tong 1987). The urban morphological characteristics of this period include restoration of the shape of West Lake and the overall outward expansion trend.

The fifth stage, from 1990 to 2000, is a period of faster expansion towards the northwest and across the east, where the wetlands and Qiantang River used to be the boundary. In the northwestern part of the city, housing construction brought by real estate development occupied vast amounts of land. The original farmland areas east of Hangsan Road, west of Jiaogong Road and north of Tianmushan Road were built into residential areas during this period. To the east, the Hangzhou East Railway Station in the northeast was constructed, while the Binjiang High-tech Industrial Development Zone in the southeast across the Qiantang River was planned. Both of them were done to alleviate the shortage of public facilities and land in the city centre but also to reflect the trend of subsequent urban development to the east. To meet the expansion of the urban area from east to west, a large number of transportation facilities were constructed during this period, including railways and highways. Apart from urban construction projects, cultural facilities were also further enriched around West Lake, and museums and memorials, such as Zhejiang Provincial Museum, National Tea Museum and Southern Song Official Kiln Museum, were constructed.

\section{The process towards conservation integrated urban planning}

By observing the five stages described above, Hangzhou scenic city cannot be formed without addressing the relationship between the West Lake scenery and city, including early completion of the city-lake combined urban form through modernization of the West Lake and city master plans, the scenery restoration and revitalization after the Lake was damaged. Later, 


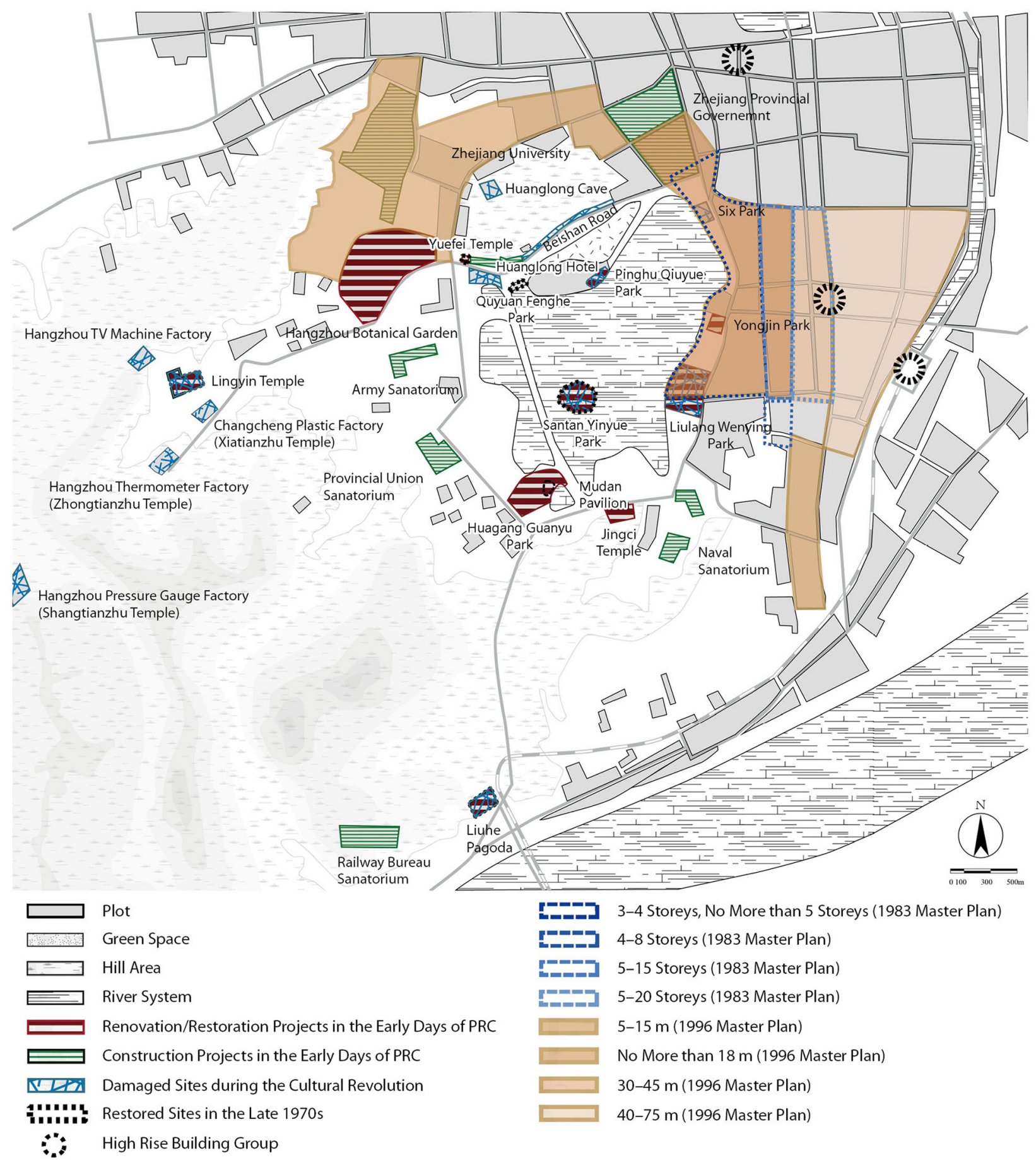

Fig. 3 Urbanisation and Conservation in the West Lake Area (Source: the authors. Data are from archives of the Hangzhou Municipal Bureau of Gardening and Cultural Relics and Hangzhou Yearbook)

conservation ideas were introduced into urban planning, which protected the West Lake Scenic area, controlled the construction of the city centre, and guided the city expansion away from the West Lake. In this context, West Lake, an essential part of Hangzhou, experienced a period of environmental improvement, a period of great damage, a period of landscape restoration and a period of comprehensive conservation (Fig. 3). The overall city experienced the five stages mentioned above and resulted in formation of a modern scenery city. As the main means to complete this process, urban planning has also undergone a development process, from simple 


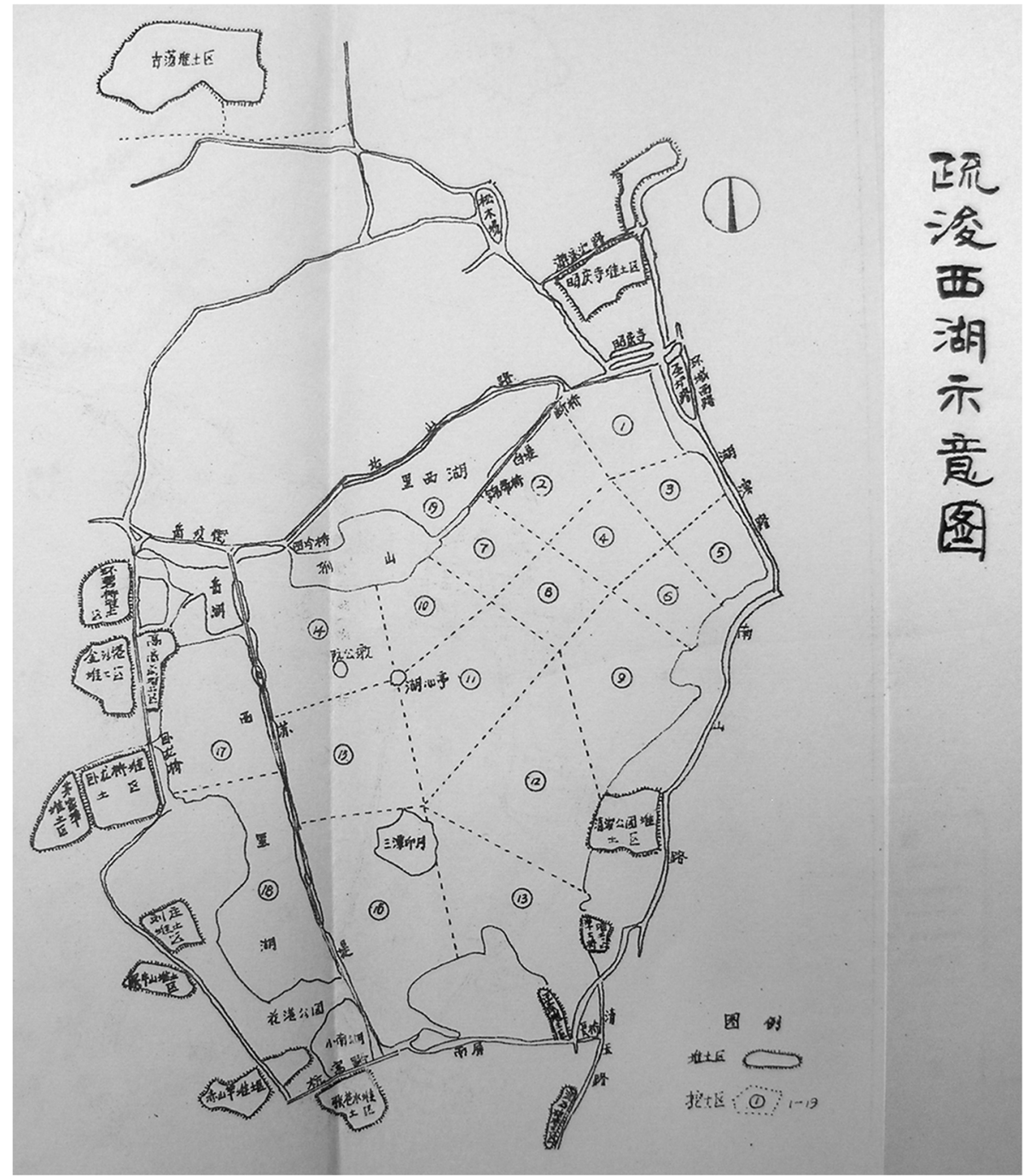

Fig. 4 Draft of West Lake Dredging Project, 1952 (Source: Archives of the Hangzhou Municipal Bureau of Gardening and Cultural Relics)

master plan in the early days of the People's Republic of China (PRC), to introducing conservation ideas into urban planning in the late 1970 s to early 1980 s and enriching the methods and tools to achieve the goal of conservation. To clarify this development process, the following two topics were further discussed. One is how protection of West Lake itself has been promoted, and the other is how the concept of conservation has been introduced into urban planning.

\section{Management towards the environmental improvement of West Lake}

In the early days of the PRC, the main purpose of West Lake governance was to improve the environment as soon as possible, with projects such as national Dredging Projects, restoration of famous temple buildings, and construction of public spaces and landscapes. All these projects were completed to meet the instruction of 'Building West Lake into a garden for working people'. During implementation of these projects, there was not much concern about protecting the scenery of West Lake, but the old pattern of West Lake was largely restored, furthering urbanisation of West Lake as an urban landscape, which provided a good foundation for the formation of a modern scenic city in Hangzhou.

The national Dredging Projects with direct funding from the central government were carried out in 1949 to restore the historic features of West Lake and to develop West Lake into a reception place for foreign guests (Hangzhou Municipal Bureau of Landscape and Cultural Relics 1990). The dredging project started with a 2-year status analysis before a special engineering department was established to take charge in 1951. According to the draft made by the department (Fig. 4), the whole 
dredging area was divided into 19 parts with several landfill areas placed around the lake. It took seven years to clean up the sediment deposited at the bottom of West Lake. With the lake mud, the low-lying land along West Lake was filled, largely on the east side, thus strengthening the ground and laying the foundation for new scenic spot construction, such as Qingbo Park, Quyuan Fenghe (Wind-Blown Lotus Flowers at a Winery) Park, and Zhaoqing Temple.

Around the lake, construction of the public space and landscape were carried out, which furthered urbanisation of the West Lake area by building modern parks. Among them, Huagang Guanyu Park was newly built and designed by the famous Chinese landscape architect, Sun Xiaoxiang, with an area of 14.65 ha. Liulang Wenying Park, Santan Yingyue (Three Pools Mirroring the Moon) Park and Pinghu Qiuyue (Autumn Moon over a Calm Lake) Park, which were all historical Ten Scenes of the West Lake and were defective due to severe damage during the domestic chaos before the PRC, underwent reconstruction and extension to become modern parks. On the west side, the construction of the Hangzhou Botanical Garden, which covers an area of 284.64 ha, started in 1956, with a goal of displaying the local plant diversity and the landscape features of West Lake.

The famous temples were also restored soon after founding of the PRC because they are an important part of the characteristics of West Lake. The temple buildings of Lingyin Temple, Fenghuang Temple and Yuefei Temple were restored with a reinforcement project, while the Buddha statues that had received poor maintenance were reconstructed. Through restoration, these artistically and historically revealing historical sites were able to be opened to public again.

\section{City master plan to complete the lake-city combined urban form}

Planning played an important guiding role in formation of the Lake City combined urban area in the early days of the PRC. In 1951, the Master Plan Draft $(1951)^{3}$ (Hangzhou Municipal People's Government 1951) was completed by the communist government, which was based on the principle of 'Boosting industrial developments, developing landscapes, beautifying West Lake, and serving the working people'. This draft proposed two contents that subsequently had a large impact on Hangzhou's morphological transformation. The first is planning of the industrial zones, one in the northern

\footnotetext{
${ }^{3}$ See these master plans in (Fu 2015).
}

area of the city and the other along the Qiantang River, which kept industrial facilities away from West Lake. The second is drafting an overall urban structure with West Lake in the centre, while planning administrative, educational and cultural buildings on the western and northern sides and recuperating buildings in the southwest. This draft clarified the relationship between the city and lake while furthering the development of a lakecity combined form through zoning.

Based on the 1951 draft and the guidance of Soviet experts, a formal master plan was issued in 1953 (Fig. 5) (Hangzhou Municipal People's Government 1953). It did not change dramatically in terms of general orientation, which was defined as a scenic city mainly for sightseeing, recuperation and culture display, and appropriate light industrial development was included in the text. However, the 1953 plan is morphologically more Baroque. In the plan drawing, West Lake is the city centre, with ring roads around the lake and radial roads coming from the lake. Referring to the actual morphological development, the City Master Plan (1953) was essential to promoting the formation of the city-lake combined urban form. It established the central position of West Lake by road network arrangement and clear urban function partitioning, while the lakeside area of West Lake was further urbanised with the construction projects of facility recuperation, such as the army sanatorium and provincial union sanatorium on the western side of the lake, naval sanatorium on the southwestern side of the lake and Hangzhou Hotel on the northern side.

However, for conservation ideas that had not yet been introduced into urban planning, those recuperation facilities and hotels inside the West Lake area were built without any control. Although most buildings were designed to be relatively small in scale and incorporate the style of traditional Chinese wooden architecture, some of them still had a certain impact on the scenery of West Lake. For example, in the southwestern area of West Lake, the Xizhao Hill area was partitioned by the provincial security office, the sanatoriums for navy, air force and army, and Zhejiang Hospital, which is mainly for senior cadres. To satisfy the demand of users, several projects, such as courtyard construction, were carried out, causing damage to the natural features of the landscape. The same situation also occurred in the Quyuan Fenghe Park, Liulang Wenying Park and Dingjia Hill areas.

\section{Demand for restoration due to loss}

The idea of conservation or protection of West Lake was not put forward until people noticed the loss in the late 1970s. The first step is restoration. During the political movements, the gardens and landmarks that comprised the West Lake scenery were regarded as Old and therefore encountered significant damage. For example, some 


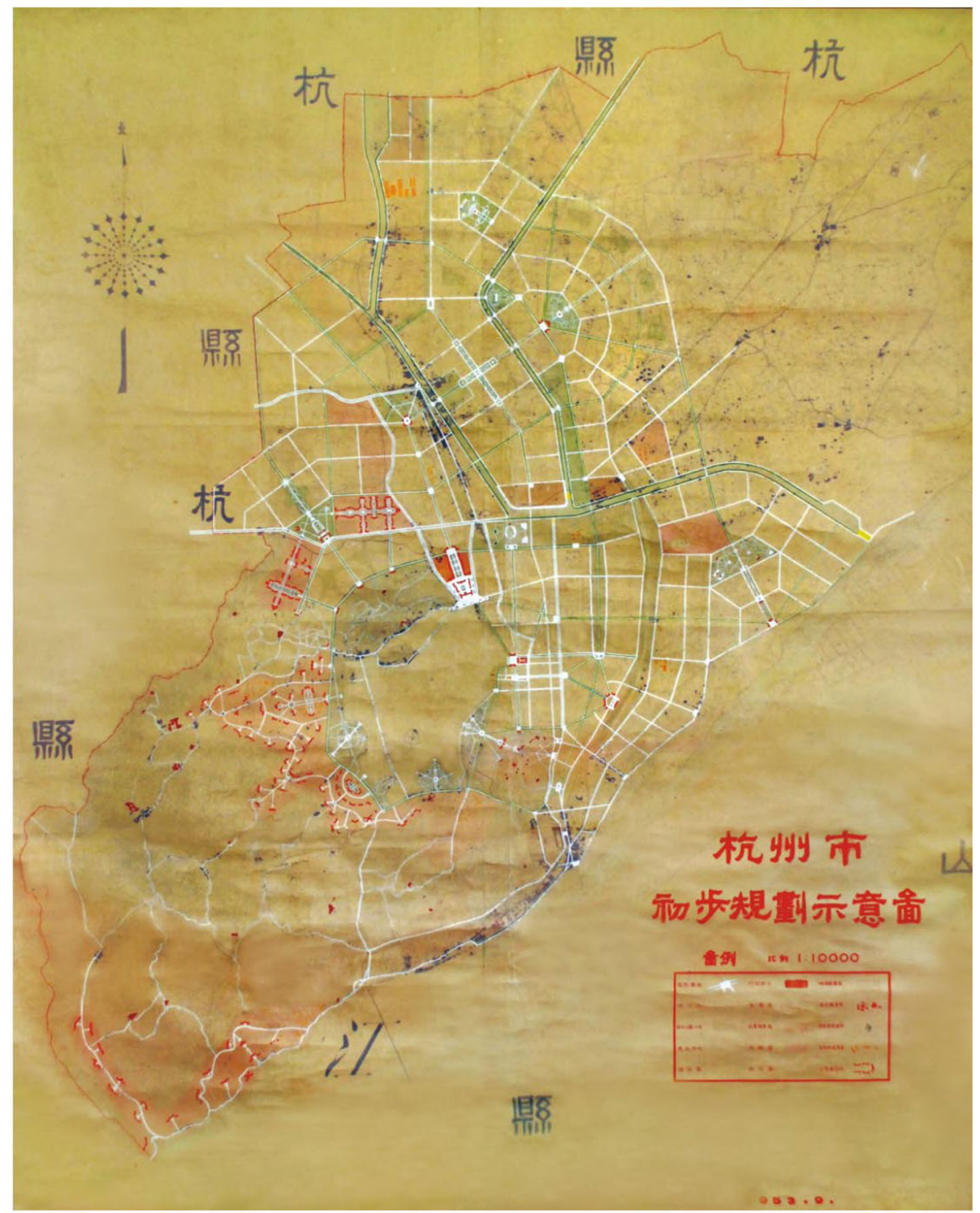

Fig. 5 Hangzhou Master Plan, 1953 (Source: Hangzhou Municipal People's Government 1953. Archives of the Hangzhou Municipal Bureau of Gardening and Cultural Relics)

green space, such as Hubin Park (Lakeside Park), and a number of historical sites, such as the three Indian temples, were occupied and transformed into office space, staff dormitories and even factories, which destroyed the garden that had been cultivated for more than ten years and the structure of historical buildings that represent traditional Chinese architectural art. On the east side of the lake, an air-raid shelter was constructed in Six Park, while the memorial archways, chairs and characteristic plants, such as lotus and rose multiflora, were torn down and removed from the green belt along Beishan Road, Quyuan Fenghe Park and Liulang Wenying Park.

Against this background, the cultural relics and historical sites, which were seriously damaged in the former period, were immediately restored. The main restoration projects consisted of those for the tablets of Ten Scenes of West Lake, such as the Shijing tablet in Huagang Guanyu Park; those for pagodas and temples, such as Lingyin Temple and Liuhe pagoda; those for the ruins, such as the Qianwang Ancestral Temple; and those for parks alongside the lake, such as Hubin Park and Quyuan Fenghe Park.

In addition, the West Lake landscape was rapidly restored through organization of the green belt around the lake, reconstruction of the lake embankment and planting of flowers and trees with diverse colours. The construction of the green belt began with the moving and closure of buildings of enterprises, organizations and troops, which occupied nearly 100 ha of land and had a negative impact on the landscape. On the southwest side 
of the lake, Quyuan Fenghe Park, which is one of the Ten Scenes and only consists of half an acre of land, a wall and a tablet pavilion by the 1980s, was replanned and constructed to be the largest park around the lake, covering 28.4 ha.

Meanwhile, with the official notification issued in 1984 to build five scenic spots around the lake, construction of a green belt around the lake was accelerated. The lakeside area along Shengtang Road, the south side area of Children's Palace, the Jinghuting area beside the Hangzhou Hotel, the Hukou area in the south of Yuefei Temple and Gushan Hill area were all restored with the relocation of original organizations and residents. The stone ridge of the circle around the lake, mainly in the Gushan Hill area, along Bai Causeway, Su Causeway and Zhao Causeway, were restored to be neater, firm and beautiful, with the entire length being $29,800 \mathrm{~m}$. Plants with diverse colours were also used to form the characteristic landscape. Through intentional arrangements, different plants were planted in different parts of West Lake, such as Chinese roses in Hubin Park, plum trees in Gushan Hill and the lotus in Quyuan Fenghe Park.

\section{Introduction of the conservation idea}

In the late 1970s, heritage conservation ideas were introduced from overseas, such as the introduction of the idea of heritage (Li 1982), which resulted in approval of the Report on the Protection of Chinese Famous Historical and Cultural Cities by the State Council in 1982 and the Cultural and Natural World Heritage Convention in 1985. With this background, the idea of urban landscape protection was proposed much earlier in Hangzhou than in other Chinese cities, mainly because West Lake had undergone great damage during political movements.

The first decisive juncture is the 1979 Conference of Urban Planning in Hangzhou, in which planning experts conducted extensive discussions on the Hangzhou master plan and the protection of West Lake. At this conference, Yang Tingbao, a professor from Nanjing Institute of Technology (now Southeast University), made a speech entitled 'Fengjing de chengshi, ru hua de jianzhu [Scenic City and Picturesque Building]'. During his speech, he advocated that the overall goal and future direction of the city must be determined from a long-term perspective, which should focus on the scene for Hangzhou city. He also stressed the need to include the conservation of West Lake into urban planning laws and regulations as soon as possible while pointing out that there were some negative and destructive factors at West Lake, such as the massive buildings and facilities causing pollution (Yang and Qi 1980).

In the following years, discussions about the urban landscape protection of West Lake also appeared in magazines, such as the paper that aired the criticism on the large-scale buildings around the lake $(\mathrm{Xu}$ et al. 1980), and in newspapers, such as the discussion about water pollution (Tong 1980), suggestions to put forward protection laws and regulations (Gong 1980) and the need to remove all illegal buildings (Li and Sun 1982). In addition, protection of the West Lake landscape was also a topic in the 1980 national political forum (He 1980).

These discussions had a significant impact on the formation of the Hangzhou Master Plan (1983), as Ge Qiming, who participated in formation of the master plan, published an article entitled 'Several Problems about the Planning of Hangzhou.' In this article, he argued that Hangzhou should be defined as a 'national key scenic tourist city' and 'the capital of the Zhejiang Province'. The government should adopt the necessary methods to build a scenic tourist city (Ge 1981).

In addition, influenced by the protection thoughts from abroad, these laws and regulations on the protection of cultural relics, urban parks, green space and scenic spots were all issued in the 1980s, expanding and improving the coverage of the protection system. The first critical law was issued by the government in 1982. The first Law for the Protection of Cultural Relics (LPCR) set up the division of cultural relic and its standards and requested that the planning department and cultural administration department to work together to formulate protection methods and include them in city master plans. In addition, to improve the urban landscape, the Tentative Regulations of Urban Parks and Green Space Administration was issued in the same year as LPCR, providing that those occupied green spaces should be improved and returned to the public. Three years later, Interim Regulations on Administration of Scenic Spots were proposed to govern and regulate activities in environmental protection and resource management. Additionally, conservation received increased attention after China became a party at the World Heritage Convention in 1985. In this context, the Urban Planning Law, which was officially announced in 1989, established the legal position of the conservation content that is included in urban planning.

Those discussions on the protection of West Lake and the introduction of relevant laws lead to a positive ideological background for the introduction of conservation ideas into urban planning and the formation of conservation integrated urban planning. As evidenced in Hangzhou, the clause about the delimitation of the West Lake scenic area and its specialized protection regulations were considered to be part of the city master plan and the regulatory detailed plan for the Hubin area (Wang and Zhu 1996).

\section{Birth of conservation integrated urban planning and its methodological development}

The conservation idea was adopted as an important part of the City Master Plan (1983) (Hangzhou Municipal 


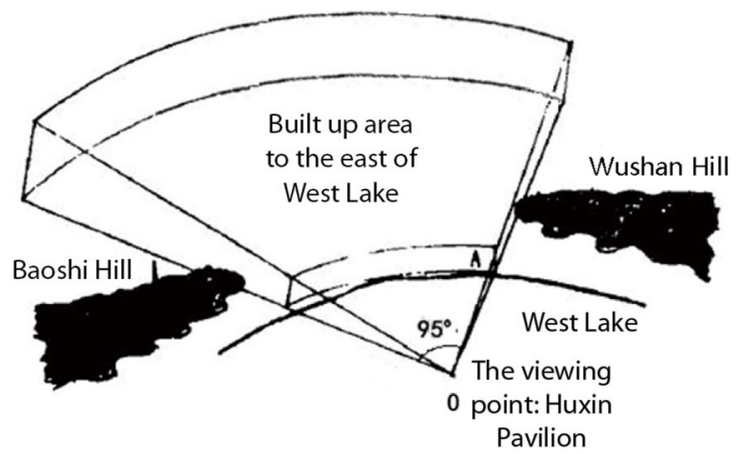

Through the three-dimensional analysis of visual fields of the fixed viewing points, the building height in the urban area is determined, and the urban skyline is designed to be coordinated with the West Lake landscape.
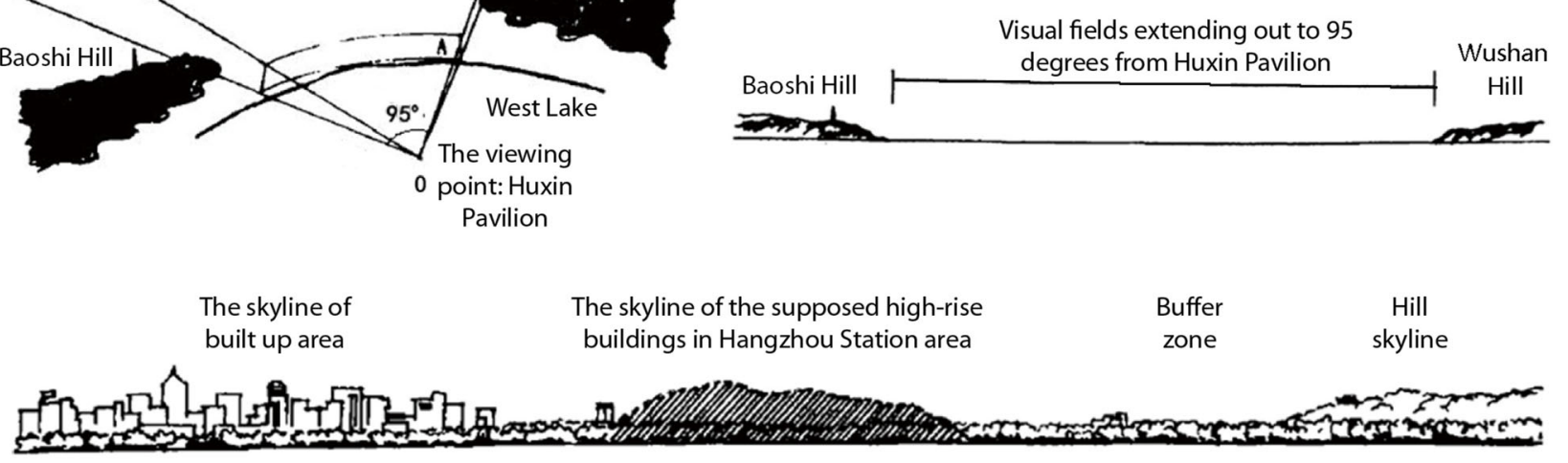

The method proposed in Hangzhou Airspace Plan (1990) is used to analyse the impact on the West Lake landscape, to determine the building height and floor area ratio of Hangzhou Station area in the detailed plan.

Fig. 6 Visual analysis method applied in Hangzhou Airspace Plan, 1990 (Source: Pan 1994. Modified by the authors)

People's Government 1983). In the fifth chapter, entitled Urban Layout, the protection scopes of the West Lake Scenic area and the peripheral protection zone were defined, with special regulations for the buildings to place them in harmony with the natural landscape. The seventh chapter, with Urban Renewal as the title, delineated the east lakeside area into four parts with specified limits on building height, materials and colour. The buildings in the Hubin area, which were planned to be a place with a concentrated distribution of tourism service facilities, were 3-4 stories; the buildings in the area between Yan'an Road and Huansha Road and on the east side of Wushan Hill were 4-8 stories; the building between Huansha Road and Zhonghe Road were 5-15 stories; and the buildings on the east side of Zhonghe Road and farther away from West Lake were no more than 20 stories. Additionally, in the ninth chapter, Landscape (lvhua in Chinese), a specific environmental improvement idea was listed for different parts of West Lake to make this area more characteristic of diverse plants and landscapes. However, because urban planning was in the initial stage of legalization and the government showed an ambiguous attitude towards the lakeside area for its great commercial value, this plan was not implemented in practice, although it had obvious positive and progressive significance.

The analytical method applied in Hangzhou Airspace Plan (1990) (Fig. 6) was more precise than that of the 1983 master plan. This plan, which was completed by the Hangzhou Planning and Design Institute, was proposed with the background that damage to the buildings in the landscape became more conspicuous, as there were more high-rise buildings constructed on the east side of West Lake after the reform and opening up. In the formation of this plan, image synthesis technology and perspective analysis methods were used to analyse the outline of the visible area when looking at the city from the West Lake centre, leading to the conclusion that the contour line of the city should be in harmony with that of the hills around West Lake by including height limits for the buildings. Thus, the urban planning bureau carried out visual simulation analyses of more than one hundred plots in the urban area and the planned buildings to ensure these new buildings would not have a negative impact on the West Lake landscape.

The City Master Plan (1996), which was implemented to meet the needs of city expansion, adopted a more detailed analysis to divide the protected area in comparison with the former ones. By using the method and result of the Hangzhou Airspace Plan (1990), the plan text delineated several zones with targeted height limits of $15-20 \mathrm{~m}$, $30-45 \mathrm{~m}$, and $40-75 \mathrm{~m}$, taking the lakeside as the most strictly controlled area. The height limit system also included hilly areas closely related to West Lake, such as Baoshi Hill and Wushan Hill, with a limit up to $18 \mathrm{~m}$. These detailed zoning restrictions improved the manoeuvrability of the conservation integrated planning, leading to the formation of the middle zone between the West Lake Scenic area and the urban builtup area, which played an important role in obtaining a smooth connection between the West Lake landscape and the urban landscape while preserving the characteristics of the West Lake area. 
The visual analysis and height limit method applied in the formation of the Hubin Regulatory Detailed Plan (1996) was more complex. This plan, which was completed by the Nanjing Institute of Technology, selected three analysis viewpoints, with Huxin Pavilion (Mid-lake Pavilion) as the main viewpoint and Jindai Bridge and Santan Yingyue as the secondary viewpoints. From these three sites, the impact of each Hubin district block on the sight line was quantified. If the block can be seen from all three sites, it would be defined as a block with a higher impact, leading to a stricter height limit. Through this sophisticated analysis process, the specialized control index of each block was determined.

\section{Discussion and conclusions}

Based on the Hangzhou Yearbook, the drawing of various editions of master plans and city maps, this study observed the development process in Hangzhou from the 1950s to the 1990s through morphological analysis. To further analyse the critical junctures and influencing factors, the morphological analysis did not define the urban fringe as most other morphological papers but selected three changing features, the size of the urbanised area, the length of the roads, and the number of construction projects on a large scale, which could quantify and measure the speed and characteristics of urban development. The result of the analysis is that the development process of Hangzhou is divided into five stages, and further analysis of the influencing factors of the five stages shows that protection of West Lake and the introduction of conservation ideas into urban planning have a significant impact on the formation of contemporary scenic cities in Hangzhou.

For West Lake, the 1950s to the 1990s covered the period of environmental improvement, urbanisation, landscape restoration and comprehensive conservation. In the 1950s, management methods were applied to improve the environment of West Lake. Meanwhile, under the guidance of master plans, the area around the lake was urbanised because construction projects of recuperation facilities and hotels were carried out inside West Lake, leading the urbanised area to continue to expand westward. After the Cultural Revolution, the landscape was immediately restored through multiple restoration projects of cultural relics, historical sites and green space around the lake in the late 1970s and 1980s. Comprehensive conservation, which was carried out in the late 1980s and 1990s, maintained historical landscape features by integrating urban planning and putting forward restrictions on the overexploitation of the West Lake area and urban area.

Urban planning also experienced a preliminary formation period, the concept development period, the idea embodiment period and the method advancement period. Urban planning directed the formation of an initial modern scenic city in Hangzhou through the implementation of city master plans and urbanisation of West Lake in the 1950s. The conservation idea was further developed through discussions on the protection of West Lake after the ten-year calamity in the late 1970s and had a positive impact on the formation of the 1983 master plan. In the 1983 master plan, the conservation idea was introduced into urban planning for the first time, leading to delineation of four height control areas, which are on the east side of the lake with specified limits on building height, materials and colour. In the 1990s, with idea development and legislation promotion, conservation integrated urban planning was further developed with the advancement of multiple analysis methods. With synthesis technology, the perspective analysis method and visual simulation analysis, conservation integrated urban planning helped the West Lake area maintain its features and created a middle zone between the West Lake Scenic area and urbanised area.

As analysed above, it is the traditional landscape features, mainly presented in the city-lake combined urban form, that differentiates Hangzhou from any other cities in the world. This city-lake urban form has undergone the early formation period of before the PRC, the preliminary development period in the 1950s, great damage during political movements, a weakening period under the impact of high rise buildings and a re-development period with conservation integrated urban planning. During the whole process, Hangzhou maintained the contemporary urban characteristics of scenic cities against this background of rapid advancement by restoring the historical scenery of West Lake through multiple projects and the introduction of the conservation concept into urban planning.

This conservation concept topic can be discussed further if we extend the research period to beyond 2000, such as how the construction in West Lake for world heritage declaration affects urban development. However, considering that the urbanised area in Hangzhou experienced great expansion after 2000, with a rapid rise from $177.18 \mathrm{~km}^{2}$ in 2000 to $615.22 \mathrm{~km}^{2}$ in 2018 (Hangzhou Statistics Bureau 2019), it would be better to put this content together with the other two world heritage sites, the Great Canal and sites of the Liangzhu Culture, and examine them within the scope of the new city area.

\section{Abbreviations \\ UIA: International Union of Architects; PRC: People's Republic of China; LPCR: Law for the Protection of Cultural Relics}

Acknowledgements

We appreciated Mr. Bao Haihan for providing two valuable interviews. We also thank Prof. Hao Li, Prof. Plácido González Martínez for their valuable advice, which help us improve this article. 


\section{Authors' contributions}

Shulan Fu contributed to the conception of the study; Panpan Jin performed the data and map analyses; All authors wrote the manuscript; The authors read and approved the final manuscript.

\section{Authors' information}

Shulan Fu is an Associate Professor of the Department of Urban Planning at Zhejiang University and also a KFAS-Kyujanggak Fellow (2018-2019) at Seoul National University. Research interests include urban planning history of modern China and cultural heritage practices in Asia.

Panpan Jin is a postgraduate student of the Department of Urban Planning at Zhejiang University.

\section{Funding}

This article is supported by the National Natural Science Foundation of China (Grant No. 2017YFC0702504) and the 'Korea Foundation for Advanced Studies'/ 'Chey Institute for Advanced Studies'. The funding funded the data collection of the study.

\section{Availability of data and materials}

All data are fully available without restriction.

\section{Competing interests}

The authors declare that they have no competing interests.

Received: 1 May 2020 Accepted: 7 September 2020 Published online: 23 October 2020

\section{References}

Barke, Michael. 2003. Urban Landscape Regions and Conservation: New Approaches and Problems in Antequera, Malaga Province, Spain. Urban Morphology 7 (1): 3-13

Barrett, Heather Joy. 1996. Townscape Change and Local Planning Management in City Centre Conservation Areas: The Example of Birmingham and Bristol. PhD diss., University of Birmingham, England.

Bienstman, Hiske. 2007. Morphological Concepts and Urban Landscape Management: The Cases of Alkmaar and Bromsgrove. PhD diss., University of Birmingham, England.

Chen, Yong. 2006. Chengshi kongjian: xingtai, leixing yu Yiyi-Suzhou gucheng jiegou xingtai yanhua yanjiu [Urban Space: Form, Type and Significance-Study on the Evolution of Suzhou Ancient City Form]. Nanjing: Southeast University Press.

Conzen, M.R.G. 1960. Alnwick, Northumberland: A Study in Town-Plan Analysis. Publication no. 27. London: Institute of British Geographers.

Fu, Juan. 2010. Jindai Yueyang chengshi zhuanxing he kongjian zhuanxing yanjiu [Researchs on Yueyang City'S social and spatial transformation 1899-1949]. Beijing: China Architecture and Building Press.

Fu, Shulan. 2015. Hangzhou shi fengjing chengshi de xingcheng shi: Xihu yu chengshi de xingtai guanxi yanjin guocheng yanjiu [The Formation History of Hangzhou Scenic City: Study on the Evolution Process of the Morphological Relations between the West Lake and the City]. Nanjing: Southeast University Press.

Fu, Shulan. 2016. Shan-Shui Myth and History: The Locally Planned Process of Combining the Ancient City and West Lake in Hangzhou, 1896-1927. Planning Perspectives 31 (3): 363-390.

Fu, Shulan, and Panpan Jin. 2019. Urban planning and heritage conservation: Morphology generation of the contemporary Scenic City in Hangzhou. Nicosia: Paper Presented in the XXVI International Seminar on Urban Form.

Ge, Qiming. 1981. Guanyu Hangzhou shi guihua ruogan wenti de tantao [Several Problems about the Planning of Hangzhou]. City Planning Review 4: 31-39.

Gong, Yuling. 1980. Jianyi zhiding fengjingqu baohufa he guanli tiaoling [Suggestion on the Formation of laws and Regulations on the Protection and Management of Scenic Spots]. Guang Ming Daily. 10 September 1980.

Hangzhou Municipal Bureau of Landscape and Cultural Relics. 1990. Xihu Fengjing yuanlin (1949-1989) [West Lake landscape architecture (1949-1989)]. Shanghai: Shanghai Science and Technology Press.

Hangzhou Municipal People's Government. 1951. Hangzhoushi quyu jihua zongtu [The 1951 Master Plan Draft]. Archives of Hangzhou Urban Construction Archives.
Hangzhou Municipal People's Government. 1953. Hangzhou shi chubu guihua shiyitu [City Master Plan (1953)]. Archives of Hangzhou Urban Construction Archives.

Hangzhou Municipal People's Government. 1958. Hangzhoushi chengshi guihua tu [Hangzhou Master Plan (1958)]. Archives of Hangzhou Urban Construction Archives.

Hangzhou Municipal People's Government. 1964. Hangzhoushi chengshi guihua tu [Hangzhou master plan (1964)]. Archives of Hangzhou Urban Construction Archives.

Hangzhou Municipal People's Government. 1983. Hangzhou shi chubu guihua shiyitu [City Master Plan (1983)]. Archives of Hangzhou Urban Construction Archives.

Hangzhou Municipal People's Government. 1988. Hangzhou nianjian (1987) [Hangzhou City yearbook (1987)]. Hangzhou: Hongqi Press.

Hangzhou Municipal People's Government. 1989. Hangzhou nianjian (1988) [Hangzhou City yearbook (1988)]. Hangzhou: Hongqi Press.

Hangzhou Municipal People's Government. 1990a. Hangzhou nianjian (1989) [Hangzhou City yearbook (1989)]. Hangzhou: Hangzhou University Press.

Hangzhou Municipal People's Government. 1990b. Hangzhou nianjian (1990) [Hangzhou City yearbook (1990)]. Hangzhou: Hangzhou University Press.

Hangzhou Municipal People's Government. 1991. Hangzhou nianjian (1991) [Hangzhou City yearbook (1991)]. Hangzhou: Hangzhou University Press.

Hangzhou Municipal People's Government. 1992a. Hangzhou nianjian (1992) [Hangzhou City yearbook (1992)]. Hangzhou: Zhejiang University Press.

Hangzhou Municipal People's Government. 1992b. Hangzhoushi chengshi zongti guihua xiugai buchong tu [Hangzhou master plan revision (1992)]. Archives of Hangzhou Urban Construction Archives.

Hangzhou Municipal People's Government. 1993. Hangzhou nianjian (1993) [Hangzhou City yearbook (1993)]. Hangzhou: Zhejiang University Press.

Hangzhou Municipal People's Government. 1994. Hangzhou nianjian (1994) [Hangzhou City yearbook (1994)]. Hangzhou: Zhejiang University Press.

Hangzhou Municipal People's Government. 1995. Hangzhou nianjian (1995) [Hangzhou City yearbook (1995)]. Hangzhou: Zhejiang University Press.

Hangzhou Municipal People's Government. 1996a. Hangzhou nianiian (1996) [Hangzhou City yearbook (1996)]. Hangzhou: Zhejiang University Press.

Hangzhou Municipal People's Government. 1996b. Hangzhou shi zongti guihua [City Master Plan (1996)]. Archives of Hangzhou Urban Construction Archives.

Hangzhou Municipal People's Government. 1997. Hangzhou nianjian (1997) [Hangzhou City yearbook (1997)]. Hangzhou: Hangzhou Press.

Hangzhou Municipal People's Government. 1998. Hangzhou nianjian (1998) [Hangzhou City yearbook (1998)]. Hangzhou: Zhonghua Book Company.

Hangzhou Municipal People's Government. 1999. Hangzhou nianjian (1999) [Hangzhou City yearbook (1999)]. Hangzhou: Zhonghua Book Company.

Hangzhou Municipal People's Government. 2000. Hangzhou nianjian (2000) [Hangzhou City yearbook (2000)]. Hangzhou: Zhonghua Book Company.

Hangzhou Statistics Bureau. 2019. Hangzhou tongji nianjian 2019 [Hangzhou Statistical Yearbook 2019]. Beijing: China Statistics Press.

Hangzhou Urban and Rural Construction Chronicles Committee. 2002. Hangzhoushi chengxiang jianshe zhi [Hangzhou Construction Chronicles]. Hangzhou: Zhonghua Book Company.

He, Zhibin. 1980. Qiangjiu Xihu de da hao he shan [The Urgent Need to Protect the Landscape of West Lake]. Guang Ming Daily 11 September 1980.

Hou, Li. 2018. Building for Oil: Daging and the Formation of the Chinese Socialist State. Boston: Harvard University Asia Center.

Kropf, Karl. 1996. Urban Tissue and the Character of Towns. Urban Design International 1 (3): 247-263.

Li, Hao. 2016. The Planning of Eight Key New Industrial Cities. Beijing: China Architecture and Building Press.

Li, Ling, and Yuemu Sun. 1982. Ying yansu chuli zai Xihu fengjing qu weizhang jianzhu de wenti [The Problem of Illegal Constructions in West Lake Scenic Spot Should Be Dealt with Seriously]. Guang Ming Daily. (21 July 1982).

Li, Shutian. 2017. Gaige kaifang yilai Hangzhou chengshi kongjian xingtai yanbian yanjiu [Research on the Evolution of Urban Spatial Form in Hangzhou since Reform and Opening-up]. PhD diss., Zhejiang University, China.

Li, Xiongfei. 1982. Lishi wenhua mingcheng jianzhu yichan de baohu [Protection of Architectural Heritage in Historic and Cultural Cities]. City Planning Review 3: $5-13$.

Pan, Hang. 1994. Xihu fengjing yu Hangzhou chengshi kongjian sheji [West Lake Landscape and Hangzhou Urban Space Design]. Time Architecture 33 (4): 3843. 
Tong, Wanshu. 1980. Rang mingzhu chong fang guangcai-_Xihu de wuran yu jinghua [Make West Lake Beautiful Again, Pollution and Purification of West Lake]. Guang Ming Daily. (6 June 1980).

Wang, Liping. 1999. Tourism and spatial change in Hangzhou, 1911-1927. In Remaking the Chinese City: Modernity and National Identity, 1900-1950, ed. Joseph W. Esherick, 107-120. Honolulu: University of Hawaii Press.

Wang, Zhiming, and Ziyu Zhu. 1996. Hangzhou hubin diqu jiucheng gaijian guihua yu xihu jingguan Bao Hu [Urban Renewal: Case Studies]. City Planning Review, no. 3: 4-7.

Whitehand, J.W.R. 1987. Urban Morphology. In Historical Geography: Progress and Prospect, ed. M. Pacione. London: Croom Helm.

Whitehand, J.W.R., Kai Gu, and S.M. Whitehand. 2011. Fringe Belts and Socioeconomic Change in China. Environment and Planning. B, Planning \& Design 38 (1): 41-60.

Whitehand, J.W.R., and Gu. Kai. 2007a. Extending the Compass of Plan Analysis: A Chinese Exploration. Urban Morphology 11 (2): 91-109.

Whitehand, J.W.R., and Gu. Kai. 2007b. Urban Conservation in China: Historical Development, Current Practice and Morphological Approach. Town Planning Review 78 (5): 643-670.

Wu, Fulong, Jiang Xu, and Anthony Gar-on Yeh. 2007. Urban Development in Post-reform China: State, Market, and Space. London: Routledge Press.

Wu, Jing, and Qingliang Ma. 1990. Chengshi bianyuan qu kongjian jiegou yanhua de jizhi fenxi [Mechanism Analysis of Spatial Structure Evolution in Urban Fringe]. Planning Review 2: 38-42+64.

Wu, Wen. 2004. Xihu fengjing mingsheng qu de lishi yange yu fazhan yanjiu (1949-2004) [The Study of the Development of the West Lake Scenic Area (1949-2004)]. Master's thesis, Tsinghua University, China.

Xu, Yicheng, Shuxiang Xi, Guangfu Zheng, et al. 1980. Lvyou Ivguan sanyi [Three Qustions about the Tourist Hotel]. The Architect 3: 30-34.

Yang, Tingbao, and Kang Qi. 1980. Fengjing de chengshi, ru hua de jianzhu [Scenic City and Picturesque Building]. The Architect 2: 66-68.

Yang, Xiaoru. 2008. The Blend of the Nature and Humanity-Exploring the Protection and Renovation Approach for the Sustainable Development of West Lake Scenic Area, Hangzhou. Chinese Landscape Architecture 3: 47-48.

Yao, Sheng, Jintang Chen, and Yinsheng Tian. 2013. Kang Ze'en chengshi xingtai quyuhua lilun zai Zhongguo yingyong de kunjing ji pojie [The Difficulties in the Application of M.R.G. Conzen's Urban Morphological Regionalization Method in China and How to Solve It]. Urban Development Studies 20 (03): 1-4.

Yao, Sheng, Yinsheng Tian, and Jintang Chen. 2012. Chengshi xingtai quyuhua lilun jiqi zai yichan baohu zhong de zuoyong Theory of Urban Morphological Regionalization and Its Application in Heritage Protection] City Planning Review 11: 47-53+66.

Yu, Yunda, and Baogen Tong. 1987. Hangzhou Xihu bian da bian mei le The West Lake in Hangzhou Has Become Bigger and More Beautiful]. People's Daily. 1 February 1987.

Zhang, Jiantao. 2003. Planning, Morphology and Change in China's Conservation Areas: A Case Study of Shanghai. PhD diss., University of Liverpool, England.

Zhang, Peng. 2008. Dushi xingtai de lishi Geng Ji: Shanghai gonggong zujie shizheng fazhan yu dushi bianqian yanjiu [A Study on the Relatiobship between Municipal Construction and Transformation of Urban Space in the International Settlement of Shanghai]. Shanghai: Tongji University Press.

Zhang, Rouran. 2017. World Heritage Listing and Changes of Political Values: A Case Study in West Lake Cultural Landscape in Hongzhou, China. International Journal of Heritage Studies 23 (3): 215-233.

Zheng, Sheng, and Lin Lin. 2002. 1990 nian yilai guonei chengshi xingtai yanjiu pingshu [A Review of Urban Form Research in China since 1990]. City Planning Review 7: 59-64+92.

Zhou, Xia. 2005. Guangzhou chengshi xingtai yanjin [Urban Form Evolution of Guangzhou]. Beijing: China Architecture and Building Press.

Zhu, Qian. 2014. China's Pre-reform Urban Transformation: The Case of Hangzhou during the Cultural Revolution (1966-1976). International Development Planning Review (2): 181-203

Zhu, Qian. 2015. From the First Five-Year Plan to the Cultural Revolution: The Prereform Urban Transformation of Hangzhou, China. Planning Perspectives 30 (4): 571-595.

Zou, Deci. 2014. Xin Zhongguo chengshi guihua fazhan shi yanjiu [China's Urban Planning History Research]. Beijing: China Architecture and Building Press.

\section{Publisher's Note}

Springer Nature remains neutral with regard to jurisdictional claims in published maps and institutional affiliations.

\section{Submit your manuscript to a SpringerOpen ${ }^{\odot}$ journal and benefit from:}

- Convenient online submission

- Rigorous peer review

- Open access: articles freely available online

High visibility within the field

- Retaining the copyright to your article

Submit your next manuscript at $\boldsymbol{\nabla}$ springeropen.com 